\title{
ISSN 1823-626X
}

\section{Journal of Fundamental Sciences}

\author{
available online at http://jfs.ibnusina.utm.my
}

\section{Photocatalytic degradation of basic and reactive dyes in both single and binary systems using immobilized $\mathrm{TiO}_{2}$}

\author{
Siew-Teng Ong $^{1}{ }^{1}$, Chnoong-Kheng Lee ${ }^{2}$, Zulkarnain Zainal ${ }^{3}$, Pei-Sin Keng ${ }^{4}$ and Sie-Tiong Ha ${ }^{1}$ \\ ${ }^{1}$ Faculty of Science, Engineering and Technology, Universiti Tunku Abdul Rahman, Jalan Universiti, Bandar Barat, 31900, Kampar Perak, Malaysia. \\ ${ }^{2}$ Institut Kimia Malaysia, Wisma IKM 127B, Jalan Aminuddin Baki Taman Tun Dr Ismail 60000 Kuala Lumpur, Malaysia. \\ ${ }^{3}$ Department of Chemistry, Faculty of Science, Universiti Putra Malaysia, 43400 Serdang Selangor, Malaysia. \\ ${ }^{4}$ International Medical University, No.126, Jalan 19/155B, Bukit Jalil,57000 Kuala Lumpur, Malaysia. \\ Accepted 30 November 2009, Available online 15 December 2009
}

\begin{abstract}
In order to avoid the separation process of fine titanium dioxide $\left(\mathrm{TiO}_{2}\right)$ photocatalyst at the end of the treatment, a simple and effective method was explored to immobilize $\mathrm{TiO}_{2}$ nanoparticles on a support material. In this paper, the effectiveness of using immobilized $\mathrm{TiO}_{2}$ supported on glass plates to remove Basic Blue 3 (BB3) and Reactive Orange (RO16) from single and binary dye solutions was investigated. The photocatalytic degradation of both dyes was investigated under the illumination of either UV or sunlight. The percentage of dye removal increased with increasing irradiation time and the maximum number of dip coatings that can be applied was ten. For all the dye solutions studied, the percentage of dye removal decreased with increasing number of usage of immobilized $\mathrm{TiO}_{2}$. Due to the ease of usage and good photocatalytic efficiency, the findings showed the potential application in decolouring organic dyes for pollution prevention.
\end{abstract}

| $\mathrm{TiO}_{2}$ | Immobilization | Basic dyes | Reactive dyes | Binary dyes | Photocatalytic degradation |

( 2009 Ibnu Sina Insitute. All rights reserved. http://dx.doi.org/10.11113/mjfas.v5n2.291

\section{INTRODUCTION}

Dyes are characterized by their ability to absorb or emit light in the visible range (400-800 nm). Man has made use of dyes since prehistoric times, for example in decorating their bodies and in colouring the furs and skins that they wore. This clearly shows that dyes had and still have a profound anthropological, psychological, esthetic, functional and economic impact on society.

The demand and the usage for dyes have continuously increased in many industries such as textile, paper, plastics and cosmetics. However, the presence of dyes even in trace quantities is highly undesirable as it reduces the light penetration into water thereby decreasing the efficiency of photosynthesis in aquatic plants and resulting in impairment on their growth. Thus, the ecosystem of streams can be seriously affected. Consequently water contamination originated from the dyeing and finishing in textile industry has become a major concern.

The photocatalytic mineralization of pollutants, especially organic pollutants has generated much interest. In the past, most of the studies related to such photodegradation reactions have been carried out using a suspension form [1]. Anatasetype titanium dioxide $\left(\mathrm{TiO}_{2}\right)$ is a semiconductor that has attracted much attention for its potential application in the decomposition of various environmental pollutants in both gaseous and liquid phases [2,3]. When $\mathrm{TiO}_{2}$ is illuminated with light energy greater than the bandgap energy $(\lambda<380 \mathrm{~nm})$, it can act as a photocatalyst to mineralize toxic and bioresistant organic compounds from aqueous solution to non-toxic and safer compounds.

However, due to the small particle size of the $\mathrm{TiO}_{2}$, a post-treatment catalyst recovery stage involving microfiltration is necessary. Post-treatment catalyst recovery would be undesirable on industrial scale as it would add to the capital and operating costs of the treatment. Consequently, many researchers have immobilized $\mathrm{TiO}_{2}$ onto various solid supports to avoid the problem of separation and recovery of photocatalyst [4-6]. Due to the same reason, the present study is focused on a simple and effective method to immobilize $\mathrm{TiO}_{2}$ nanoparticles on a support material for photocatalytic decolorization of both basic and reactive dyes which are in widespread use in many industries. The main advantage of this immobilized photocatalytic system is that the photocatalyst can be re-used and when needed, it is also possible to regenerate this immobilized catalyst. 


\section{EXPERIMENTAL}

The $\mathrm{TiO}_{2}$ powder P-25 (mainly in anatase form, mean particle size of $30 \mathrm{~nm}$, BET surface area of $50 \mathrm{~m}^{2} / \mathrm{g}$ ) from Degussa (Frankfurt, Germany) was used as the photocatalyst in this study. The immobilization of $\mathrm{TiO}_{2}$ on glass plate (2 inch $\times 4$ inch $\times 0.12$ inch) was carried out according to the method reported by McMurray et al. [7] with minor modification. $1 \mathrm{~g}$ of $\mathrm{TiO}_{2}$ was added to $20 \mathrm{ml}$ of $99.9 \%$ methanol solution. The resulting mixture was stirred continuously until all the $\mathrm{TiO}_{2}$ powders were uniformly dispersed. The glass plate was dipped into the mixture (considered as 1 time dip coating). The cationic dye BB3 (C.I. $=51004,40 \%$ dye content Sigma) and anionic dye RO16 (C.I. $=17757,50 \%$ dye content Aldrich) were used as the sorbates in this study without further purification.

Irradiation experiments of dye solutions were carried out by stirring $500 \mathrm{ml}$ of $100 \mathrm{mg} / \mathrm{l}$ dye solution in a $1000 \mathrm{ml}$ beaker with immobilized $\mathrm{TiO}_{2}$ at room temperature $\left(25 \pm 2^{\circ} \mathrm{C}\right)$ for 8 hours unless otherwise stated. Aeration was provided by bubbling air into the reaction solution by an air pump to ensure a constant supply of oxygen . UV-irradiation was provided by a UV lamp $100 \mathrm{~W}, 220 \mathrm{~V}$. At given intervals of irradiation, approximately $5 \mathrm{ml}$ of the solution was withdrawn from the reservoir and the concentration of dye in the solution was determined using a Shimadzu 160B double beam UVVis spectrophotometer. The photodegradation of binary dye was similar to that of single dye solution. All measurements were made at the wavelength corresponding to maximum absorption; for BB3, $\lambda_{\max }=654 \mathrm{~nm}$ and for RO16, $\lambda_{\max }=494 \mathrm{~nm}$.

In order to compare the efficiency between the immobilized and suspended systems in the removal of dye from single dye solution, the amounts of $\mathrm{TiO}_{2}$ used in both systems were kept constant. The effect of light source was studied by using two different light sources, namely UV lamp and sunlight. The number of $\mathrm{TiO}_{2}$ dip coatings studied was 2, 4, 6, 8, and 10 times. Photodegradation experiments were repeated 5 times before the glass plates were recycled. The recycle process was carried out by soaking the used $\mathrm{TiO}_{2}$ glass plates in distilled water and exposing them under sunlight for one day. After recycling, the $\mathrm{TiO}_{2}$ glass plates were reused in order to study the efficiency of the recycled $\mathrm{TiO}_{2}$ glass plates in the subsequent photodegradation process.

\section{RESULTS \& DISCUSSION}

A direct comparison of efficiency between suspended and immobilized systems was carried out. The percentage of removal was calculated by using the equation given below:

$$
\% \text { Removal }=\frac{C_{o}-C}{C_{0}} \times 100
$$

where $\mathrm{C}_{\mathrm{o}}$ is the initial dye concentration and $\mathrm{C}_{\mathrm{t}}$ is the concentration of dye at time $t$. Under the same experimental condition, $13 \%$ of $\mathrm{BB} 3$ was removed using $\mathrm{TiO}_{2}$ in suspended form whereas immobilized $\mathrm{TiO}_{2}$ was only capable to remove $10 \%$ of the same dye. The results of colour removal efficiency of RO16 also showed that between the suspended and immobilized $\mathrm{TiO}_{2}$, a higher percentage of colour removal was obtained using $\mathrm{TiO}_{2}$ suspension. In order to ascertain whether the difference is significant, statistical analysis using the Duncan test was carried out. The result from the Duncan test [8] shows that the difference was significant (probability, $\mathrm{p}<0.05$ ). One possible explanation for this phenomenon is that overlapping of the photocatalyst might occur during immobilization process, thus reducing the contact surface. (Immobilization of $\mathrm{TiO}_{2}$ onto glass plates was carried out by 10 times of repetitive dip coating of the glass plates using $\mathrm{TiO}_{2} /$ methanol solution). The thickness of more than one layer may hinder the illumination of the photocatalyst. Mahmoodi et al. [9] also reported that the use of suspended $\mathrm{TiO}_{2}$ powder is more efficient due to the large surface area of catalyst available for reaction. Although the immobilized system resulted in a reduction of photodegradation efficiency, it can still be considered as a promising method for colour removal because it can avoid the post-treatment for catalyst recovery which would be undesirable at industrial scale.

The numbers of $\mathrm{TiO}_{2}$ dip coating studied were 2, 4, 6, 8 and 10 times. By using 2 times dip coated $\mathrm{TiO}_{2}$ glass plates with the irradiation time of 480 minutes, the percentage of colour removal for BB3 and RO16 from single dye solutions was $34.5 \%$ and $29.7 \%$, respectively. Under the same conditions, the percentage of colour removal for BB3 and RO16 by 10 times dip coated $\mathrm{TiO}_{2}$ glass plates increased to $44.1 \%$ and $38.2 \%$, respectively. Similarly, in the binary dye solutions, the percentage of colour removal increases about $8 \%$ for both dyes with increasing number of dip coatings from 2 to 10 times. The amount of $\mathrm{TiO}_{2}$ coated on the glass plate is proportional to the number of dip coating; the increase in catalyst loading on the glass plates will increase the number of active sites and thereby increase the percentage of colour removal. In all the 
experiments, a smooth and linear trend was seen throughout the irradiation time and this implies that the photoactivity of the catalyst was efficient within the reaction time. Table 1 lists the values of half time $\left(t_{1 / 2}\right)$ and correlation coefficients of pseudo-first order kinetics of photodegradation of all the dye solutions with different numbers of $\mathrm{TiO}_{2}$ dip coatings. The values of $\mathrm{t}_{1 / 2}$ shown were calculated using the equation as follows:

$$
\text { when } \mathrm{C} / \mathrm{C}_{\mathrm{o}}=0.5 \text {, }
$$

$$
\mathrm{t}_{1 / 2}=0.693 / \text { apparent rate constant }
$$

The high values of correlation coefficients indicate that the data fit the kinetics model well. It was shown that the colour removal rate increased with $\mathrm{TiO}_{2}$ loading and this is related to the formation of hydroxyl radicals which are the critical species in the photodegradation processes. The calculated $t_{1 / 2}$ decreased with increasing number of dip coatings and this confirms the positive influence of the increased number of $\mathrm{TiO}_{2}$ active sites in the photodegradation of the dyes studied. However, the efficiency of photodegradation would increase up to certain extent with increase in photocatalyst concentration and become constant or decrease thereafter [10,11]. The higher amount of photocatalyst is thought to be beneficial in the total removal of waste and its removal rate because it increases the number of active sites on the photocatalyst surface, which in turn increases the number of hydroxyl, and superoxide radicals.

Thus, an attempt was made to find the optimum photocatalyst loading for the photodegradation of both dyes in this work. However the optimum catalyst loading cannot be determined in this study because the maximum number of $\mathrm{TiO}_{2} \mathrm{dip}$ coating that can be done was 10 and additional coating results in the cracking of the $\mathrm{TiO}_{2}$ film on the glass plate.

Table 1: Pseudo first-order correlation coefficients and half-time values for the photodegradation of single and

\begin{tabular}{|c|c|c|c|}
\hline Dye & $\begin{array}{c}\text { Number of } \mathrm{TiO}_{2} \\
\text { dip coating (times) }\end{array}$ & $\begin{array}{l}\text { Half-time, } t_{1 / 2} \\
\quad(\min )\end{array}$ & $\begin{array}{c}\text { Correlation coefficient } \\
\left(\mathbf{R}^{2}\right)\end{array}$ \\
\hline \multirow{5}{*}{$\begin{array}{c}\text { BB3 } \\
\text { (single) }\end{array}$} & 2 & 969.2 & 0.9546 \\
\hline & 4 & 840.9 & 0.9560 \\
\hline & 6 & 833.8 & 0.9674 \\
\hline & 8 & 733.4 & 0.9648 \\
\hline & 10 & 726.1 & 0.9650 \\
\hline \multirow{5}{*}{$\begin{array}{c}\text { RO16 } \\
\text { (single) }\end{array}$} & 2 & 891.6 & 0.9854 \\
\hline & 4 & 789.3 & 0.9917 \\
\hline & 6 & 785.7 & 0.9936 \\
\hline & 8 & 701.2 & 0.9928 \\
\hline & 10 & 633.6 & 0.9909 \\
\hline \multirow{5}{*}{$\begin{array}{c}\text { BB3 } \\
\text { (binary) }\end{array}$} & 2 & 603.9 & 0.9891 \\
\hline & 4 & 500.8 & 0.9873 \\
\hline & 6 & 459.3 & 0.9975 \\
\hline & 8 & 427.6 & 0.9935 \\
\hline & 10 & 390.3 & 0.9886 \\
\hline \multirow{5}{*}{$\begin{array}{c}\text { RO16 } \\
\text { (binary) }\end{array}$} & 2 & 480.2 & 0.9854 \\
\hline & 4 & 437.5 & 0.9917 \\
\hline & 6 & 397.3 & 0.9936 \\
\hline & 8 & 364.0 & 0.9928 \\
\hline & 10 & 335.3 & 0.9909 \\
\hline
\end{tabular}
binary dye solutions with different numbers of $\mathrm{TiO} 2$ dip coatings 
Figures 1 and 2 show the effect of light sources in the colour removal of BB3 and RO16 from single and binary dye solutions, respectively. As shown in the figures, a higher percentage of colour removal was observed for reactive dye than basic dye and this is most probably due to the colour intensity of the dye itself. Apart from this, it is also evident that the percentage of colour removal in single dye solutions is comparable when using UV or sunlight. However, the experimental results of photodegradation of BB3 and RO16 in binary dye solutions (Figure 2) show that the removal efficiency of these dyes was higher using UV light than solar light. This may be due to the fluctuation in sunlight intensity as the generation of electron and hole pair is closely related to the light intensity. The production of electron and hole is a necessity for the reaction with water, hydroxide ion or oxygen to form powerful oxidizing species for the photodegradation process. Thus, a decrease in the colour removal efficiency would be anticipated if the intensity of the light source is lower.

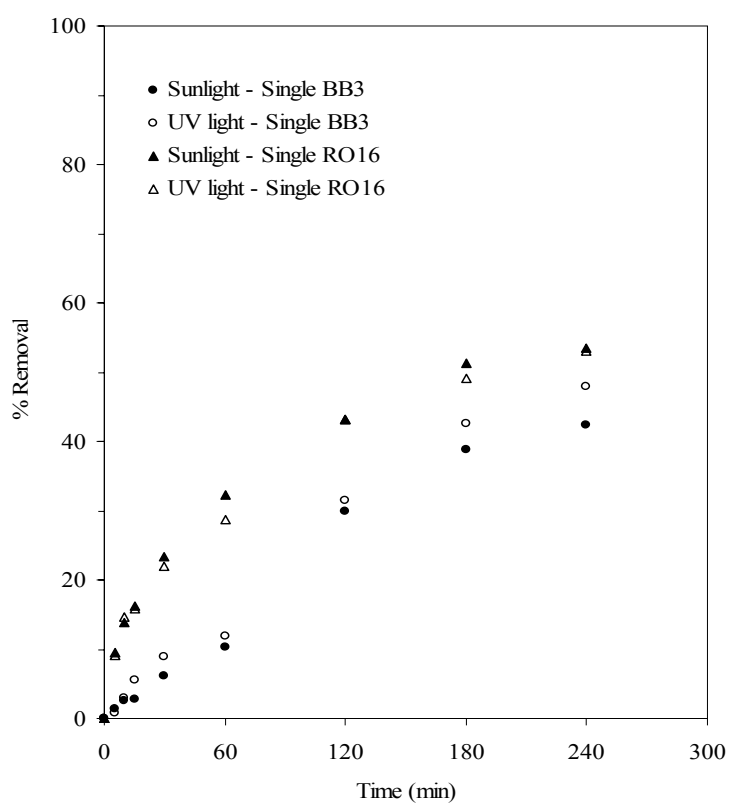

Figure 1: Effect of light sources for the photodegradation of BB3 and RO16 from single dye solutions

Similar behaviour was reported previously [11-13]. They suggested that the photocatalytic degradation increased with increasing light intensity because higher light intensity generated more photons which were required for the electron transfer from the valence band to the conduction band of a semiconductor photocatalyst. Hence, the rate of degradation increased when more radiations fell on the catalyst surface and produced more hydroxyl radicals for degradation process.

The regeneration of $\mathrm{TiO}_{2}$ photocatalyst was one of key steps to make this type of heterogeneous photocatalysis technology applicable for practical usage. Thus, a study on the repetitive usage and recycle of dip coated $\mathrm{TiO}_{2}$ glass plates was carried out. For all the dye solutions studied, the percentage of colour removal decreases with increasing number of usage. In the removal of BB3 from single dye solution (Figure 3), it was observed that the colour removal efficiency decreased from $46.7 \%$ to $34.2 \%$ after five times reuse whereas a decrease of $11.5 \%$ was noted in the case of RO16. With the increase in repetitive usage of dip coated $\mathrm{TiO}_{2}$ glass plates up to 5 cycles in binary dye solution, a two-fold decrease in the colour removal efficiency was observed for both BB3 and RO16.

This implies that when the dip-coated $\mathrm{TiO}_{2}$ glass plates were used repetitively for photodegradation of dye solutions with the same initial concentration, the photocatalytic activity of the dip-coated $\mathrm{TiO}_{2}$ glass plates decayed gradually. The decrease in the colour removal efficiency may be due to the non-negligible adsorbed dye molecules on the $\mathrm{TiO}_{2}$ glass plates. These adsorbed dye molecules will hinder the photocatalyst from being illuminated by the light source and hinder the formation of electron-hole pairs. The greater decrease in the percentage of colour removal in the binary dye solutions can be explained by the formation of residues that was evident towards the end of the experiments. Similar observation was reported on the photocatalytic degradation of azo-dyes in the presence of $\mathrm{TiO}_{2}$ aqueous suspension [14].

Similar observation was reported in the photodegradation of Rhodamine B by titania films [15]. They suggested that with the repetitive cycles, the gradual loss of beneficial radicals can be discerned, which resulted in gradual decrease in the photocatalytic activity. 


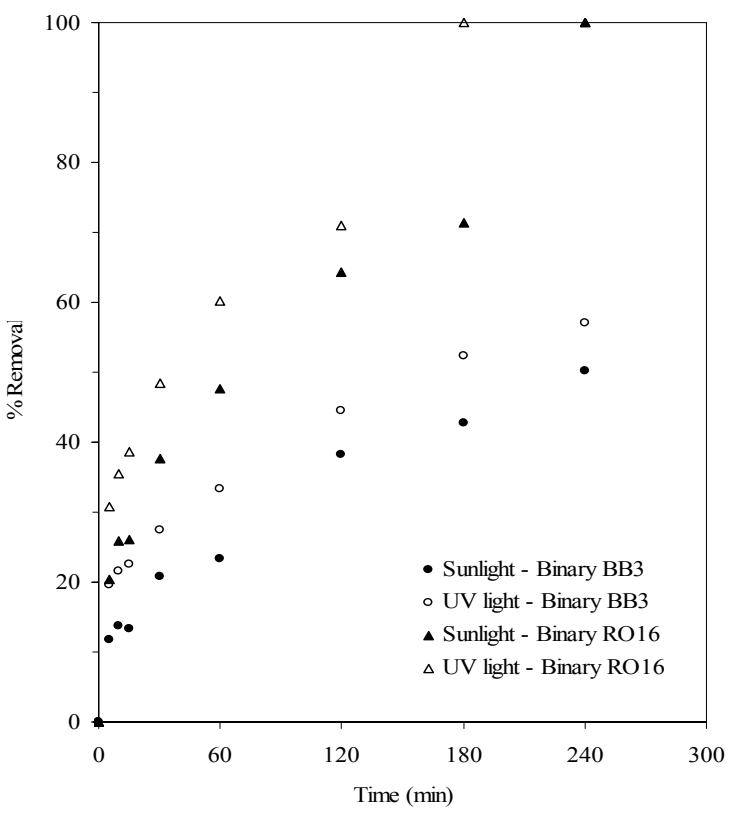

Figure 2: Effect of light sources for the photodegradation of BB3 and RO16 from binary dye solutions

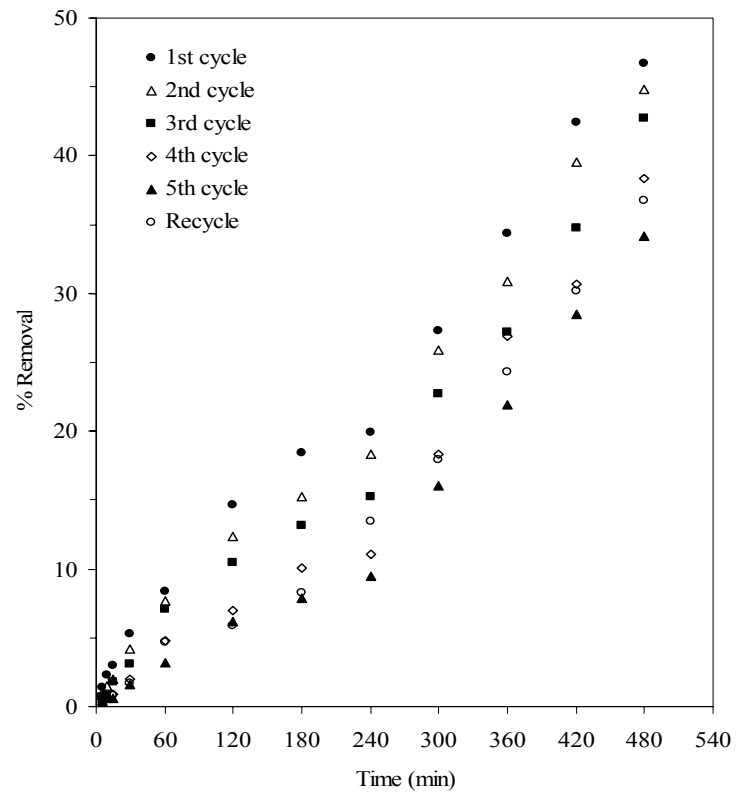

Figure 3: Repetitive usage of dip coated $\mathrm{TiO}_{2}$ in the removal of $\mathrm{BB} 3$ from single dye solutions

The recycling process of $\mathrm{TiO}_{2}$ glass plates was carried out and the results show that the efficiency of the immobilized $\mathrm{TiO}_{2}$ did not revert to that initial stage, instead it was at the level of $4^{\text {th }}$ and $5^{\text {th }}$ repetitive usage. Similar observation was reported in the photodegradation of Congo Red [16]. This indicates that the dye molecules are strongly adsorbed on the $\mathrm{TiO}_{2}$ glass plates and it cannot be removed by the recycling method applied. 


\section{CONCLUSION}

From this study, it is evident that the immobilized $\mathrm{TiO}_{2}$ is capable in removing both $\mathrm{BB} 3$ and $\mathrm{RO} 16$ under the illumination of either UV or sunlight. The results revealed that the $\mathrm{TiO}_{2}$ loading plays an important role in determining the photocatalytic decolouring efficiency of the dyes. For all the dye solutions studied, the percentage of dyes removal decreased with increasing number of usages of immobilized $\mathrm{TiO}_{2}$. However, the immobilized $\mathrm{TiO}_{2}$ still displayed a good performance in the removal of organic dyes. Thus, further studies on the intermediates produced in the photodegradation process will be carried out to ensure that no undesirable hazardous compounds were formed before complete mineralization takes place.

\section{ACKNOWLEDGEMENT}

We acknowledge financial support from the Ministry of Science, Technology and Innovation of Malaysia via IRPA grant number 08-02-04-0655-EA001 and NSF grant for S. T. Ong.

\section{REFERENCES}

[1] D.S. Kim and Y.S. Park, Chem. Eng. J., 116 (2006) 133-137.

[2] P.F. Fu, Y. Luan and X.G. Dai, J. Molecular Catalysis, 221 (2004) 81-88.

[3] C.H. Chiou, C.Y. Wu, R.S. Juang, Sep. Purif. Technol., 62 (2008) 561-566.

[4] M. Nikazar, K. Gholivand and K. Mahanpoor, Desalination, 219 (2008) 293-300.

[5] N.M. Mahmoodi and M. Arami, J Photochem. and Photobio. B: Bio., (2009) 20-24.

[6] E. Rego, J. Marto, P.S. Marcos and J.A. Labrincha, Appl. Catalysis A, General (2008)

[7] T.A. McMurray, J.A. Byrne, P.S.M. Dunlop, J.G.M. Winkelman, B.R. Eggins and E.T. McAdams, Appl. Catal. A: General, 262 (2004) 105-110.

[8] D.B. Duncan, Biometrics, 11 (1955) 1-42.

[9] N. M. Mahmoodi, M. Arami, N. Y. Limaee and N. S. Tabrizi, J. Coll. Inter. Sci., 295 (2006) 159-164.

[10] A. P. Toor, A. Verma, C. K.. Jotshi, P.K.. Bajpai and V. Singh, Dyes and Pigments, 68 (2006) 53-60.

[11] M.A. Behnajady, N. Modirshahla and R. Hamzavi, J. Hazard. Mater., 133 (2006) 226-232.

[12] C. Karunakaran and S. Senthilvelan, Catal. Comm., 6 (2005) 159-165.

[13] M. Qamar, M. Muneer and D. Bahnemann, J. Environ. Manage., 80 (2006) 99-106.

[14] E. Adamek, W. Baran and A. Makowski, Chem. Eng. J., 145 (2008) 242-248.

[15] J. M. Wu and T. W. Zhang, J Photochem. and Photobio. A: Chem., 162 (2004) 171-177.

[16] M.A. Behnajady, N. Modirshahla, M. Mirazamohammady, B. Vahid and B. Behnajady, J. Hazard. Mater., 160 (2008) 508-513. 